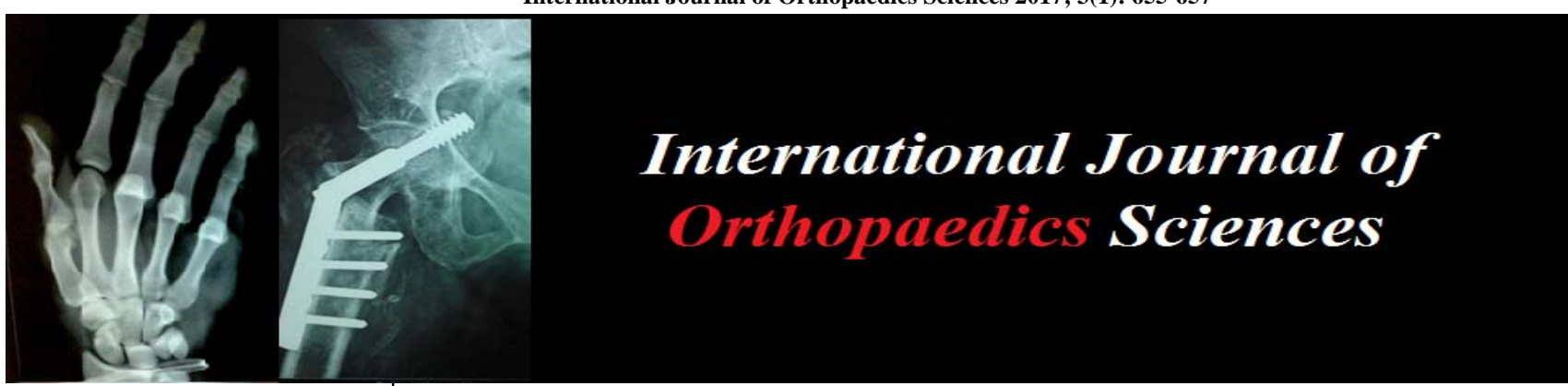

ISSN: $2395-1958$

IJOS 2017; 3(1): 655-657

(C) 2017 IJOS

www.orthopaper.com

Received: 06-11-2016

Accepted: 07-12-2016

Dr. Sunil Kumar TR

Senior Resident, ESIC Medical

College and Model Hospital \&

PGIMSR, Bangalore,

Karnataka, India

Dr. Satish Babu DG

Senior Resident, ESIC Medical

College and Model Hospital \&

PGIMSR, Bangalore,

Karnataka, India

\section{Profile of patients with osteoarthritis of knee}

\section{Dr. Sunil Kumar TR and Dr. Satish Babu DG}

DOI: http://dx.doi.org/10.22271/ortho.2017.v3.i1j.96

Abstract

Introduction: Severe radiological osteoarthritis (grade 3 or grade 4) was uncommon under age 45 years. Overall, differences between men and women were small except for hips and knees; however, severe radiological osteoarthritis was found in a higher proportion in most of the joints in women

Methodology: The study was conducted on patients attending orthopaedics outpatient department, who had early osteoarthritis knee diagnosed by American College of Rheumatology Criteria and staged as per Ahlbacks radiological grading. The sample size studied was 32 patients of which 16 patients in each group

Results: In our study all the patients had osteoarthritis in both the knees with 10 patients having more involvement of the right knees and left knees were involved in 6 patients in Group 1 and in Group 2 the predominance of involvement of the side was equal between right and left knees with 8 patients each having more involvement on right or left knees

Conclusion: In our study group 1 had 5 patients grade 1, and 11 patients had grade2 of Ahlbacks grading of osteoarthritis knee

Keywords: Ahlbacks grading, osteoarthritis knee, radiological osteoarthritis

\section{Introduction}

Osteoarthritis (OA) is a chronic degenerative disorder that is characterized by a loss of articular cartilage ${ }^{[1]}$, in the synovial joints which is characterized by sclerosis subchondral bone thickening, marginal osteochondral outgrowths (osteophytes). Several risk factors have been identified, such as obesity, occupation, higher age, biomechanics and increased dynamic loading of the joint and joint injury, and invoves the weight bearing joints like hip and knee joint ${ }^{[2]}$

The ageing is not the sole predictor of the disease and the only risk factor, but play an important role in early symptomatic appearance of the disease, which cannot be ignored ${ }^{[3]}$. Because, with ageing there is decrease in the chondroitin sulfate and hyaluronic acid which replaces the keratin sulfate. Osteoarthritic cartilage lesions show a decrease in chondroitin sulfate concentration and chain length and a decreased ratio of chondroitin sulfate to compounds containing keratin sulfate plus glycoprotein.

The progressive fatigue failure with associated changes in the structure of cartilage due to altered chondrocyte metabolism causes the reduction in biomechanical properties with age. Boschetti et al ${ }^{[1]}$ in their study reported that the biomechanical properties (the static compressive modulus, the dynamic compressive modulus and the static tension modulus) of the osteoarthritic cartilage were inferior to that of the normal cartilage.

Van Saase et al in their survey in 1989 showed that the women were at a higher risk of having severe OA. The prevalence of mild and severe radiological osteoarthritis was investigated in a random sample of 6585 inhabitants of a Dutch village using the criteria described by Kellgren and Lawrence ${ }^{[4]}$. The prevalence of radiological osteoarthritis increased strongly with age and was highest for cervical spine (peak: men $84.8 \%$, women $84.3 \%$ ), lumbar spine (peak: $71.9 \%$, women $67.3 \%$ ), and distal interphalangeal joints of the hands (peak: men $64.4 \%$, women $76 \%$ ). Severe radiological osteoarthritis (grade 3 or grade 4) was uncommon under age 45 years. Overall, differences between men and women were small except for hips and knees; however, severe radiological osteoarthritis was found in a higher proportion in most of the joints in women.
Dr. Sunil Kumar TR

Senior Resident, ESIC Medica College and Model Hospital \& PGIMSR, Bangalore, Karnataka, India 
Srikanth et al. In 2005 studied the sex differences in osteoarthritis (OA) by performing a meta-analysis of sex differences in osteoarthritis prevalence, incidence and severity of osteoarthritis. They conducted a MEDLINE search (19662003) retrieving all studies regarding epidemiology of OA during that period. Their results demonstrated the presence of sex differences in OA prevalence and incidence, with females generally at a higher risk. Males had a significantly reduced risk for prevalence of OA in the knee. Females, particularly those $>55$ years, tended to have more severe OA in the knee than the other sites.

The treatment for the osteoarthritis include physical exercise, bracing, anti-inflammatory drugs and intra articular injections. Non-steroidal anti-inflammatory drugs (NSAIDs) are often used in conservative management to relieve pain. Paracetamol (Tylenol/acetaminophen), is commonly used to treat pain from OA.

Physical therapy and rehabilitation may provide short-term pain relief. Bosomworth et al. found that moderate exercise led to improved functioning and decreased pain in people with osteoarthritis of the knee. For individuals without osteoarthritis, strong level II evidence was found (limited by problems with blinding and randomization) and for those with pre-existing knee osteoarthritis, robust level I evidence was available. Patients with established osteoarthritis were shown to derive uniform benefit to physical functioning, with reduction of pain and disability, using aerobic, muscle strengthening, aquatic, or physiotherapy-based exercise modalities. Provided trauma was avoided, moderate exercise did not lead to acceleration of knee osteoarthritis, whether or not there is evidence of pre-existing disease. In either case there appeared to be improved physical functioning and reduction of pain and disability in those who exercised ${ }^{[5]}$.

Other modalities studied in the treatment of osteoarthritis are glucosamine, chondroitin sulphate or both combined. However, most treatments do not modify the natural history or progression of OA, and thus are not considered curative. Recently platelet rich plasma and mesenchymal stem cells (MSCs) have been used as cellular vectors in the treatment of osteoarthritis as a disease modifying modality.

\section{Methodology:}

Our study was prospective randomised double blinded comparative study between use of autologous mesenchymal stem cells with platelet rich plasma (PRP) and platelet rich plasma alone in early osteoarthritis knee. A total no. of 32 patients were studied and they were randomised into two groups group 1 mesenchymal stem cells with platelet rich plasma and group 2 platelet rich plasma alone by computer generated algrorithm table each group had 16 patients. The study was conducted on patients attending orthopaedics outpatient department, who had early osteoarthritis knee diagnosed by American College of Rheumatology Criteria and staged as per Ahlbacks radiological grading.

The sample size studied was 32 patients of which 16 patients in each group. The patients were selected after going through the inclusion and exclusion criteria mentioned below.

\section{Inclusion Criteria}

1) Patients with painful knee joint

2) Grade 1 or Grade 2 Osteoarthritis knee as per Ahlbacks radiographic staging

\section{Exclusion Criteria}

1) Osteoarthritis secondary to joint inflammatory diseases (eg- rheumatoid arthritis, ankylosing spondylitis etc)

2) Patients with co-existing low back ache or any other hip joint disease.

3) Patients with other diseases, affecting the knee joint like crystal arthropathy, symptomatic chondrocalcinosis, acute synovitis, excessive joint effusion $(>100 \mathrm{ml})$, cystic disease around the knee joint(eg-popliteal cyst)

4) Advanced stage of osteoarthritis

5) Bone marrow suppression

6) Co morbidities like pregnancy, cancer, immunosuppression

All patients suitable for inclusion into the study were informed of the nature of the study in detail and a written consent was obtained.

The patients were examined clinically regarding VAS score KOOS score and WOMAC score recorded each patient was investigated by routine blood tests investigation X ray, MRI.

\section{Interventional procedure \\ Group 1}

Once the mesenchymal stem cell are ready, the PRP was prepared from the patient blood on the day of interventions. The subject was placed in supine position with knee in slight flexion and under full aseptic precautions 8-10 ml PRP was mixed with around 2-3 $\mathrm{ml}$ of autologous cultured mesenchymal stem cell and injected by lateral approach with an 18-20 $\mathrm{G}$ needle followed by $2 \mathrm{ml}$ of calcium chloride injected. After $30 \mathrm{~min}$ of observation the patient was discharged, advised three day antibiotics and paracetamol for analgesia.

\section{Group 2}

The subject was placed in supine position with knee in slight flexion and under full aseptic precautions 8-10 ml of PRP was injected by lateral approach with an 18-20 G needle followed by $2 \mathrm{ml}$ calcium chloride. After $30 \mathrm{~min}$ of observation the patient was discharged, and advised three day course of antibiotics and analgesia.

\section{Results}

The mean age of the patients was 52.38years $(\mathrm{SD} \pm 7.839)$ with a range of 42-66 years in group 1 and in group 2 was 51.44 years $(\mathrm{SD} \pm 8.030)$ with a range of 38 -64years. The two groups were comparable with normal distribution and no significant difference with $p$ value 0.747 was observed.

\section{Height}

Mean height of the patients was $160.25 \mathrm{~cm}(\mathrm{SD} \pm 6.90 \mathrm{~cm})$ in group1 and mean height of $162.43 \mathrm{~cm}(\mathrm{SD} \pm 6.50 \mathrm{~cm})$ in group2. The two groups were comparable in terms height and no significant difference was observed between the groups with $p$ value 0.364 .

\section{Weight}

Mean weight in group1 was $68.5 \mathrm{~kg}(\mathrm{SD} \pm 7.74 \mathrm{~kg})$ and in group 2 the mean weight was $73.81 \mathrm{~kg}(\mathrm{SD} \pm 7.05 \mathrm{~kg})$. The two groups were also comparable in terms of weight with no significant difference observed with $\mathrm{p}$ value 0.51 .

\section{Body Mass Index (BMI)}

In group 1 the mean $\mathrm{BMI}$ was $26.75 \mathrm{~kg} / \mathrm{m}^{2}(\mathrm{SD} \pm 2.32)$ and group2 BMI was $28.00 \mathrm{~kg} / \mathrm{m} 2$ ( $\mathrm{SD} \pm 2.89$ ), Two groups were comparable in terms of body mass index with statistically insignicant with $\mathrm{p}$ value of 0.188 . 
Table 1: Distribution of age, height, weight and BMI

\begin{tabular}{|c|c|c|c|c|c|}
\hline & \multicolumn{2}{|c|}{ Group 1 } & \multicolumn{2}{c|}{ Group 2 } & \multirow{2}{*}{ p-value } \\
\cline { 2 - 5 } & Mean & S.D. & Mean & S.D. & \\
\hline Age (in years) & 52.38 & 7.839 & 51.44 & 8.446 & .747 \\
\hline Height $(\mathrm{cm})$ & 160.250 & 6.9041 & 162.438 & 6.5010 & .364 \\
\hline Weight $(\mathrm{Kg})$ & 68.500 & 7.7460 & 73.813 & 7.0543 & .051 \\
\hline BMI $\left(\mathrm{kg} / \mathrm{m}^{2}\right)$ & 26.750 & 2.3238 & 28.000 & 2.8983 & .188 \\
\hline
\end{tabular}

\section{Sex distribution}

In group 1 all patients were females and group 2 included 13 females and 3 male patients. The two groups were comparable which was statistically insignificant $(p=0.226)$

Table 2: Distribution of sex in study groups

\begin{tabular}{|c|c|c|c|c|}
\hline & & Group 1 & Group 2 & p-value \\
\hline \multirow{2}{*}{ Female } & Number & 16 & 13 & \multirow{3}{*}{0.226} \\
\cline { 2 - 4 } & Percent & $100.0 \%$ & $81.3 \%$ & \multirow{2}{*}{0.22} \\
\hline \multirow{2}{*}{ Male } & Number & 0 & 3 & \\
\cline { 2 - 4 } & Percent & $.0 \%$ & $18.8 \%$ & \\
\hline
\end{tabular}

\section{Side Wise Distribution of the Knees}

All our patients in both groups had involvement of osteoarthritis in both the knees

Table 3: Knee distribution in the study

\begin{tabular}{|c|c|c|c|}
\hline Knee & Bilateral & Group 1 & Group 2 \\
\hline \multirow{2}{*}{ Baseline } & Number & 16 & 16 \\
\cline { 2 - 4 } & Percent & $100 \%$ & $100 \%$ \\
\hline
\end{tabular}

\section{Grading of Osteoarthritis}

In group1 5 patients had Ahlback grade 1 and 11 patients Ahlback grade 2 osteoarthritis whereas group 2 had 6 patients of grade 1 and 10 patients grade 2 osteoarthritis of knee. The two groups were comparable in terms of ahlbacks grading and no significant difference was obseverd with $\mathrm{p}$ value of 0.710 .

Table 4: Ahlback' s grade * Group Crosstabulation

\begin{tabular}{|c|c|c|c|c|}
\hline Ahlback' s grade & & Group 1 & Group 2 & p-value \\
\hline \multirow{2}{*}{ Grade 1 } & Number & 5 & 6 & \\
\cline { 2 - 4 } & Percent & $31.3 \%$ & $37.5 \%$ & \multirow{2}{*}{0.710} \\
\hline \multirow{2}{*}{ Grade 2 } & Number & 11 & 10 & \\
\cline { 2 - 4 } & Percent & $68.8 \%$ & $62.5 \%$ & \\
\hline
\end{tabular}

\section{Discussion}

The age ranges in our study in group 1 is with a mean of 52.38years $(\mathrm{SD} \pm 7.839)$ and in group 2 with a mean age of 51.44 years $(\mathrm{SD} \pm 8.44)$. Our study included the patients with early osteoarthritis (Ahlbacks grade I and II), so the mean age of the sample was lower than that of the general osteoarthritic population. A previous study done found that the radiographic prevalence of knee OA to be $37.35 \%(n=532)$ in $60-69$ years age group; $48.17 \%(n=686)$ in $70-79$ years and $14.46 \%$ in $>80$ years with a mean of 73.27 years in their study population of 1424 subjects ${ }^{[6]}$.

In Group 1 all were females $100 \%(n=16)$, and in Group 2 there were more number of females than males $18.8 \%$ males $(n=3)$ and $81.3 \%$ females $(n=13)$. This is in accordance with the prior major studies such as the Framingham study ${ }^{7}$ that OA is more prevalent in the female population. The epidemiological study by Dieppe et al ${ }^{[8]}$ in 1991, whose study population consisted of $68.4 \%$ females (mean age 65.3 years) and $31.6 \%$ males (mean age 59.7 years).
The mean height of the patients included in Group 1 was $160.25 \mathrm{~cm}$ and in Group 2 mean height was $162.43 \mathrm{~cm}$. The mean weight in Group 1 was $68.5 \mathrm{Kg}$ and in Group was 73.81 $\mathrm{Kg}$. The mean Body mass index (BMI) in Group 1 was 26.75 $\pm 2.32 \mathrm{Kg} / \mathrm{m}^{2}$ and in Group 2 was $28 \pm 2.89 \mathrm{Kg} / \mathrm{m}^{[2]}$.

In our study Group 1 had 2 patients with normal BMI, 11 were overweight $(68.8 \%)$ and 3 were obese $(18.8 \%)$ and Group 2 had 1 patient with normal BMI, 11 were overweight $(68.8 \%)$ and 4 were obese $(25 \%)$. Felson et al ${ }^{[6]}$ found that $47.1 \%$ were overweight and $33.7 \%$ obese among the 525 osteoarthritis knee patients. So, our study population consisted of less obese but more overweight patients.

In our study all the patients had osteoarthritis in both the knees with 10 patients having more involvement of the right knees and left knees were involved in 6 patients in Group 1 and in Group 2 the predominance of involvement of the side was equal between right and left knees with 8 patients each having more involvement on right or left knees. In a study by Michael et al [9] they found that in men, the right knee is more commonly affected; in women, the right and left knees are affected with nearly equal frequency.

\section{Conclusion}

In our study group 1 had 5 patients grade 1 , and 11 patients had grade 2 of Ahlbacks grading of osteoarthritis knee. Group 2 had 6 patients of grade 1 , and 10 patients of grade 2 Ahlbacks grading of osteoarthritis knee.

\section{References}

1. Jacobson A, Brinck J, Briskin MJ, Spicer AP, Heldin. Expression of human hyaluronan synthases in response to external stimuli. Biochem J 2000; 348:29-35.

2. Amgad M, Haleem, Abdel A, Dina S, Hazem MA, Laila A Rashed et al. The Clinical Use of Human CultureExpanded Autologous Bone Marrow Mesenchymal Stem Cells Transplanted on Platelet-Rich Fibrin Glue in the Treatment of Articular Cartilage Defects: A Pilot Study and Preliminary Results. Cartilage. 2010; 1:253-261.

3. Davis MA. Epidemiology of osteoarthritis. ClinGer Med. 1988; 4:241-255.

4. Boschetti F, Peretti GM. Tensile and compressive properties of healthy and osteoarthritic human articular cartilage. Biorheology. 2008; 45:337-44.

5. Srikanth VK, Fryer JL, Zhai G, Winzenberg TM, Hosmer D, Jones G. A meta-analysis of sex differences prevalence, incidence and severity of osteoarthritis. Osteoarthritis Cartilage. 2005; 13:769-81.

6. Davis MA, Ettinger WH, Neuhaus JM, Cho SA, Hauck WW. The association of knee injury and obesity with unilateral and bilateral osteoarthritis of the knee. Am J Epidemiol. 1989; 130:278-88.

7. Felson DT, Zhang Y, Hannan MT. The incidence and natural history of knee osteoarthritis in the elderly. The Framingham Osteoarthritis Study. Arthritis Rheum. 1995; 38:1500-5.

8. Janet Cushnaghan, Paul Dieppe. Study of 500 patients with limb joint osteoarthritis. Analysis by age, sex, and distribution of symptomatic joint sites. Annals of the Rheumatic Diseases. 1991; 50:8-13.

9. Altman R, Asch E, Bloch D. Development of criteria for the classification and reporting of osteoarthritis. Classification of osteoarthritis of the knee. Diagnostic and Therapeutic Criteria Committee of the American Rheumatism Association. Arthritis Rheum. 1986; 29:1039-49. 